\title{
Stratejik İnsan Kaynakları Yönetimi Penceresinden Afet ve Acil Durum Yönetiminde İletişim
}

\author{
${ }^{* 1}$ Fatih Yaman \\ ${ }^{* 1}$ İstanbul Teknik Üniversitesi, Afet Yönetimi Enstitüsü, İstanbul, Türkiye, ORCID: 0000-0002-5412-5074
}

\begin{abstract}
Özet
Afet ve acil durum yönetimi temelde, etkin kaynak yönetimi tabanlı bir süreç yönetimidir. Yönetilecek kaynaklar, insan, takım ve malzeme olmak üzere üç bileşenden oluşmaktadır. Bu üç bileşenini en önemli halkası hiç şüphesiz insan kaynağıdır. İnsan kaynağının etkili ve verimli olarak yönetimi, karşılaşılabilecek kötü durumları en aza indirebilmek için kullanılabilecek en güçlü unsur olarak karşımıza çıkmaktadır. İletişimin, insan kaynağı yönetiminde kilit rol oynayan bir konu olduğu açık ve net olarak bilinen bir husustur. Stratejik insan kaynakları yönetiminde önemi vurgulanan iletişim yönetiminin aynı zamanda afet ve acil durum yönetiminde de temel bir alt başlık olarak karşımız çıktığı görülmektedir. $\mathrm{Bu}$ çalışma kapsamında iletişim yönetiminin bu iki konu bağlamında nasıl entegre edilebileceğine dair birtakım önerilerde bulunulacaktır.
\end{abstract}

Anahtar Kelimeler: Afet ve Acil Durum Yönetimi, Stratejik İnsan kaynakları Yönetimi, İletişim, Kamu Bilgilendirmesi,

\section{Communication in Disaster and Emergency Management from the Strategic Human Resources Management Window}

\begin{abstract}
Disaster and emergency management is basically an effective resource management based process management. The resources to be managed consist of three components: human, equipment and material. The most important item of these three components is undoubtedly the human resource. Productive and efficient management of human resources is the most powerful element that can be used to minimize possible disasters and emergencies. It is clearly known that communication is a key issue in human resource management. Communication, whose importance is emphasized in strategic human resources management, also appears as a major subtitle in disaster and emergency management issue. In this study, some suggestions will be made on how communication management can be integrated in the context of these two topics.
\end{abstract}

Key Words: Disaster and Emergency Management, Strategic Human Resources Management, Communication, Public Information

*Sorumlu Yazar: Adres: İTÜ Afet Yönetimi Enstitüsü, İTÜ Ayazağa Yerleşkesi, 34469 Maslak, ISTANBUL. E-Posta: fatih.yaman@itu.edu.tr, Tel: 02122856532 (143) 


\section{Giriş}

Afet ve acil durum yönetimi son yıllarda önemi dramatik tecrübelerle artış gösteren, çok disiplinli bir bilim dalı halini almıştır. Hem afet çeşitlerinin farklılaşması hem de etkilerinin beklenilmedik düzeyde gerçekleşmesi toplumları, ülkeleri ve bireyleri farklı tedbirler almaya yönlendirmiştir. Afet ve acil durum yönetimi konusu birçok farklı alt konuyu ihtiva eden kompleks bir bütün olarak tarif edilebilir. Temel alt başlıklardan biri olan iletişim ise oldukça önemli bir yere sahip olmakla birlikte, afet ve acil durum yönetiminin tün görev alanlarında etkin olarak doğru ve hızlı bir biçimde uygulanmak zorunda olan hayati bir konu olarak karşımıza çıkmaktadır.

Normal hayat düzeninde organizasyonların etkin yönetiminde önemli bir rol oynayan stratejik insan kaynakları yönetimindeki iletişim yönetimi bölümü de benzer şekilde organizasyonun verimliğini arttırılması noktasında kilit bir öneme sahiptir. Her iki konunun birbiri içine geçen çok ortak yönünün olması ve uygulama noktasında bu bilgi birikiminin entegre edilmesi hususunda farklı bir bakış açısı oluşturmak amacıyla bu çalışma gerçekleştirilmiştir.

\section{Stratejik İnsan Kaynakları Yönetimi Yaklaşımı}

Stratejik insan kaynakları yönetimi, 1980'li yıllar ve sonrasında personel yönetiminden insan kaynakları yönetimine geçişle birlikte stratejik bir rol üstlenmeye başlamıştır [1]. Bir örgütün amaçlarına ulaşabilmesini olası kılmak için tasarlanmış, planlı bir insan kaynakları faaliyetleri modeli olarak düşünülebilir[2]. Bu kapsamda, sürdürülebilirliği sağlamaya yönelik olarak, uzun dönem amaçlanarak oluşturulmuş örgüt vizyonuna göre, var olan insan kaynağının saptanan amaçlara doğru yönlendirme süreci olarak da tanımlanabilir.

Genel amaçları ise; çalışanları, yüksek performansa özendirmek, verimliliği arttırmak, rekabet üstünlüğü elde etmek, çalışma hayatı kalitesini geliştirmek, yetenek ve yaratıcılığı geliştirmek ve yasalar uygun iş görmek şeklinde tariflenebilir[3].

Stratejik insan kaynakları yönetiminde üç temel hedef bulunmaktadır. İnsan Kaynağını planlama, İnsan Kaynağını motive etme veya isteklendirme ve devamlılığı sağlamaya yönelik İnsan Kaynağını koruma[4].

Stratejik insan kaynakları yönetiminin temel işlevlerini de; planlama, kadrolama, değerlendirme, ödüllendirme, yetiştirme-geliştirme, iş sağl $\breve{g ̆}_{1}$ ve güvenliği, endüstri ilişkileri şeklinde tanımlamak mümkündür. Bu işlevleri gerçekleştirirken bir takım ana ilkelere göre faaliyetlerin düzenlenmesi gerekmektedir. Liyakat, insana değer verme, yansızlık, eşitlik, gizlilik, açıklık, bilimsellik, güvence ve yetiştirme -geliştirme bu ilkeleri oluşturan öğelerdir [3]. 


\section{Stratejik İnsan Kaynakları Yönetiminde İletişim}

Stratejik insan kaynakları yönetimi yönünden iletişimin önemini şöyle sıralayabiliriz:

- İletişim, kişiler ve gruplar arasında gerekli ilişkilerin kurulmasına ve bir bütün olarak işletmenin faaliyet göstermesine imkân tanıma ve işletme içerisinde ortak bir anlayış yaratma yönünden önemlidir.

- Kişileri örgüt amaçları yönünde etkili bir biçimde çalışabilmeleri için aralarındaki uyumu ve işbirliğini gerçekleştirme yönünden önemlidir.

- Örgütlerin etkin bir biçimde yönetilmesine yardım eden bir yönetim aracıdır.

- Yöneticilerin doğru ve hızlı karar almalarına yardımcı olan önemli bir unsurdur.

- Organizasyonun başarısı, tüm faaliyetlerin özünü oluşturan iletişim etkinliğinin sonuna kadara başarılı bir şekilde yararlanılması ile mümkündür[5].

İnsan kaynakları yönetiminin başarısı için etkin iletişimin koşulları şu şekilde sıralanabilir.

1. Etkin iletişim kanallarını oluşturma

2. Açık ve şeffaf yönetim anlayışının gerçekleştirilmesi

3. Katılımcı yönetim anlayışı

4. İş hedef gruplarının bilgilendirilmesi

\section{5. Çalışanların eğitilmesi ve yabancılaşmanın önlenmesi}

Kişiler arası etkin iletişimi sağlamak üzere, kişilerin kendisini ve başkalarını anlama ve kendilerini anlatma konusunda kendilerini nasıl gördüklerini net olarak görmek önemli bir etkendir. $\mathrm{Bu}$ konuda Johari penceresi adiyla literatürde yaralan ve bilinmeyen alan olarak da ifade edebileceğimiz, kişilerin birbirlerini alalamada ne kadar açık olup olmadıklarını tespit etmeye yarayan bir yaklaşım mevcuttur. Bir öz yeterlilik analizi olarak tanımlanabilir. Kişinin kendisi hakkında neleri bilip bilmediğinin yansıra diğer kişilerin kendisi hakkında neler bildiğini tanımlayıcı bir metottur. Şekilde Bilinmeyen olarak ifade edilen kısmın küçük olması istenir[6].

Ayrıca kişinin bilinen alnın genişletmesi için geri bildirim alması, başkaları tarafında bilene özelliklerinin artması için de kişinin ve başkalarının bildiği sıfatları daha fazla göstermesi önerilir[7]. Tablo 1'de gösterildiği gibi ifade edilebilir. 
Tablo 1: Jorahi penceresi yaklaşımı

\begin{tabular}{|l|l|l|l|}
\hline \multicolumn{2}{|c|}{} & \multicolumn{2}{c|}{ Kişinin Kendisi } \\
\hline \multirow{3}{*}{ Başkaları } & Bilinen & Açlinen & Bilinmeyen \\
\cline { 2 - 4 } & Bilinmeyen & Örtük/Gizli & Kör \\
\hline
\end{tabular}

Organizasyonlarda, var olan etkin iletişim sayesinde çalışanlar ve yöneticiler neyin önemli olduğunu, nelerin beklenildiğini, değișim nedenlerini, nelerin doğru ya da yanlış olabileceğini ve organizasyonun nasıl işlediğini öğrenirler. Ayrıca iletişim, organizasyonlarda bilgilendirmeyi ve görüş alışverişini, öğrenmeyi rehber olmayı, dinlemeyi ve cevap vermeyi sağlar. Tüm bu unsurların birleştirici noktası insan kaynakları yönetimi faaliyetleridir. Dolayısıyla insan kaynakları uygulamalarının etkin ve verimli yürütülmesi iletişim etkinliklerinin sağlıklı bir şekilde gelişmesini sağlayan en önemli faktör olarak ortaya çıkmakladır.

\section{Afet ve Acil Durum Yönetiminde İnsan Kaynakları Yönetiminin Rolü}

Organizasyonlarda iş sürekliliğinin kesintiye uğramaması için temel felsefe, organizasyonda bulunan tüm çalışanların iş tanımlarına ek olarak afet ve acil durumlar için de ikinci bir iş tanımlarının oluşturulmasıdır. Bu iş tanımına yönelik gerekli yetkinlikleri, eğitimler ve tatbikatlar vasitasıyla edinerek ve sürekli tekrarlayarak, olası afet ve acil durumlarda ikinci fonksiyonlarını yerine getirmek suretiyle, can, mal güvenliğini korumak, bununla beraber işletmenin en kısa sürede ve en az zararla normal rutinine dönmesine katkıda bulunmaktır. İşletmelerde ve kurumlarda genellikle bu konu tesis yönetimi, güvenlik yönetimi, idari işler birimlerinin altında faaliyet göstermektedir. Ancak “İş Sürekliliği Yönetimi”, stratejik yönetimin bir unsuru olduğu için mutlaka genel müdür ya da görevlendireceği genel müdür yardımcısı seviyesindeki bir üst düzey yöneticinin liderliğinde, insan kaynakları ve/ve ya stratejik yönetim departmanlarının öncülüğünde yürütülmesi gereken kritik bir faaliyettir[8].

Özellikle insan kaynakları yönetimi bu konuda önemli bir rol üstlenecek altyapı ve birikime sahip bir departmandır. Olası bir afet ve/veya acil durumda yönetimi sağlamak için iş liderlerinin yanı sıra acil durum planlamasına yönelik stratejilerinin geliştirilmesi ve güncellenmesinde kritik bir rol oynamalıdır[9].

Olası bir afet ve/veya acil durum karşısında organizasyon ya da çalışan üzerinde birtakım etkilerin oluştuğu bilinmektedir. Bunlardan en önemlilerinden bazıları aşağıdaki gibi sıralanabilir: organizasyon içindeki panik, kilit personel ve bilgi kaybı, işgücünde yüksek işten ayrılma oranı, düşük performansa neden olan moral ve motivasyon eksikliği, sağlıkla ilgili giderlerin artması, insan kaynakları ile ilgili maliyetli hukuk davalarının artması, olumsuz itibar ve imaj kaybı, yanlış 
bilgi akışı, liderlik ve inanç kaybı, müdahale ve iyileştirme aşamalarında psikolojik sorunların artışı ve yönetim zorlukları, işe alımları iptal etme, programlanmış eğitim programlarının iptal edilmesi. Tüm bu olumsuzluklar, stratejik insan kaynakları yönetimi aracılığı ile en az düzeye indirilebilir. Olası afet ve/veya acil durum karşısında organizasyonda ve çalışanlar üzerinde yaşanabilecek bir takım negatif etkileri, stratejik insan kaynakları yönetimi ve uygulamaları ile telafi etmek mümkündür[10]. Bu hususu bir tablo ile göstermek gerekirse (Tablo 2).

Tablo 2: Afet ve Acil durumların olası etkileri ve İnsan kaynakları yönetimi çözümleri

\begin{tabular}{|l|l|}
\hline Organizasyon ve Çalışan Üzerine Olası Etkiler & Stratejik İK Yönetimi ve Uygulamaları \\
\hline Organizasyon içindeki panik & Planlama takımı oluşturulması \\
\hline Kilit personel ve bilgi kaybı & Yetenek yönetimi ile çalışan sadakatının geliştirilmesi \\
\hline İgücünde yüksek işten ayrılma oranı & Eğitim ve profesyonel gelişim desteği \\
\hline $\begin{array}{l}\text { Düşük performansa neden olan moral ve motivasyon } \\
\text { eksikliği }\end{array}$ & $\begin{array}{l}\text { Çalışan destek programları, psikolojik destek, koçluk ve } \\
\text { mentorluk faaliyetleri }\end{array}$ \\
\hline Sağlıkla ilgili giderlerin artması & Sigorta firmaları ile poliçe güncelleme faaliyetleri \\
\hline İK ile ilgili maliyetli hukuk davalarının artması & Calıșanlar ile uzlaşma \\
\hline Olumsuz itibar ve imaj kaybı & Oüplacement politikasının yeniden düzenlenmesi \\
\hline Yanlış bilgi akışı & $\begin{array}{l}\text { Tüm dâhili iletişim kanallarının ve uygun sosyal medya } \\
\text { kanallarının kullanımı }\end{array}$ \\
\hline Liderlik ve inanç kaybı & Söylenti yönetimi \\
\hline $\begin{array}{l}\text { Müdahale ve iyileştirme aşamalarında psikolojik } \\
\text { sorunların artıșı ve yönetim zorlukları }\end{array}$ & Mentorluk \\
\hline
\end{tabular}

Afet ve acil durum yönetim planlaması yapılırken, özellikle insan kaynakları departmanları aktif olarak rol almalıdırlar. Çalışanların fiziksel, zihinsel ve psikolojik sağlıklarını, bu planlama çalışmaları esnasında göz önünden bulundurarak gerçekleştirmelidirler. Bu kapsamda aşağıda belirtilen birtakım çalışmalara hayata geçirilebilir.

İşe alım süreçleri önceliklendirilerek yeniden düzenlenmelidir. İş analizi kapsamında iş tanımı, iş gerekleri ve iş değerlemesi gibi alt unsurla da dâhil olmak üzere yeniden değerlendirilerek güncellenmelidir. Yeni teşvik ve ödüllendirme planları geliştirilmelidir. Organizasyondaki özel yeteneklere yönelik geliştirme programları tasarlanmalıdır. Uzun dönem hedeflere ulaşmak için kısa dönem hedefler tekrar gözden geçirilerek güncellenmelidir. Uzun dönem hedefler yeniden gözden geçirilerek güncellenmelidir. Stratejik hedeflere daha kolay ulaşmak amaciyla, küçük adımlardan oluşan bir yapıya dönüştürülmelidir. Organizasyonun başarıyla devam etmesini engelleyebilecek en küçük hata ya da ihmal göz önünde bulundurularak, gerekli düzeltici faaliyetler zamanında ve uygun biçimde yerine getirilmelidir. 


\section{Afet ve Acil Durum Yönetiminde İletişim}

Afet ve acil durum yöneticileri, çalışanlarına, vatandaşlarına, medyalarına ve paydaşlarına liderlik etmekten sorumludur. Olay esnasında, panik ve karışıklık ortaya çıkabilir ve her durumda soğukkanlı ve sakin kalmak afet yöneticisini temel özelliklerinden bir tanesidir. Afet ve acil durum yöneticilerinin acil bir durumu yönetmek için kullanabileceği önemli bir beceri, doğru ve etkili iletişimdir[11]. Afet ve acil durum yönetiminde iletişim önemli bir yer sahip temel alt konulardan bir tanesidir. Özellikle tüm görev alanlarında etkin olarak kullanılması gereken, müdahale aşamasında ortak bilgi merkezi adı ile ayrı bir birim olarak faaliyet gösteren ve Kamu Bilgilendirmesi görevini yürüten hayati bir fonksiyondur. İletişim yönetimi; Eğitim ve bilgilendirmek, İnsanların davranışlarını ve alışkanlıklarını değiştirme, İnsanları eyleme çağırmak, Toplum içinde kurumunuz hakkında olumlu etki yaratmak ve Bilinçlendirme kampanyaları düzenlemek ve geliştirmek için kullanılır[12].

Bilgiyi toplamak, kontrol etmek ve dağıtmak, Medya elemanları ile çalışmak İletişim kanallarını açık tutmak ve Perde arkasındaki olayları/kişileri ortaya çıkarmak amacıyla yapılan faaliyetlerdir. Ayrıca, olası afet ve/veya acil durumların yönetimi sırasında kurulan ortak bilgi merkezi de konuyla ilgili olarak değinilmesi gereken bir diğer husustur. Afet ve acil durum yönetim merkezleri ile afet ve acil durum arama ve kurtarma birlik müdürlüklerinde yerleşmiş, 24 saat esasına göre çalışan, telsiz sistemleri dâhil çeşitli iletişim sistemleri/cihazları ile donatılmış ve bu sistemleri kullanma yeterliliğine sahip personelin görevlendirildiği merkez olarak literatürümüzde tanımlanmıştır[13]. Bunun yansıra bu merkez; Çok farklı kurum ve kuruluştan gelen bilgilerin eşgüdümünü sağlar, Haber ve bilgilerdeki çelişkileri en aza indirir, Basın ve yayın organlarının ihtiyaçlarını karşılar ve Basın ve Halkla İlişkiler çalışanlarından en iyi şekilde yararlanılmasını sağlar. İletişim yönetimini bir şekilde sağlıklı yürütmek için planlama yapmak esastır. Plan, organizasyonun afet ve /veya acil durumlarda nasıl iletişim kuracağını ve olayı nasıl ele alacağını açıklamalıdır[14]. Halkı bilgilendirme, harekete geçirme, yapılan çalışmaların verimliliğini değerlendirme, Acil durum planlarının ekine Basın ve Halkla İlişkiler açıklamalarını hazırlama, Basın ve yayın organları ile devamlı iletişim halinde olma, Zaman ve bütçe kısıtlamalarına karşın değişik kaynaklar temin etme ve planlar geliştirme, aynı zamanda Kurumun gündemde kalması ve imajının kuvvetlenmesi için çalışmalar yapmak gibi unsurları içermelidir. Özellikle müdahale aşamasında etkin olarak kullanılan ortak bilgilendirme merkezi (Joint Information Center -JIC) vasıtası ile iletişimin etkin ve verimli bir şekilde yürütülmesi mümkündür. Ortak bilgilendirme merkezi, sahadan gelen tüm bilgileri organize etme, entegre etme ve koordine etme mekanizmasını sağlar. Eldeki planları, protokolleri ve prosedürleri kullanarak ilgili tüm paydaşlar arasında zamanında, doğru, erişilebilir ve tutarlı iletişimi temin eder. Bu yapıyı şekil 1'deki gibi bir organizasyon şemasında görmek mümkündür[15]. 


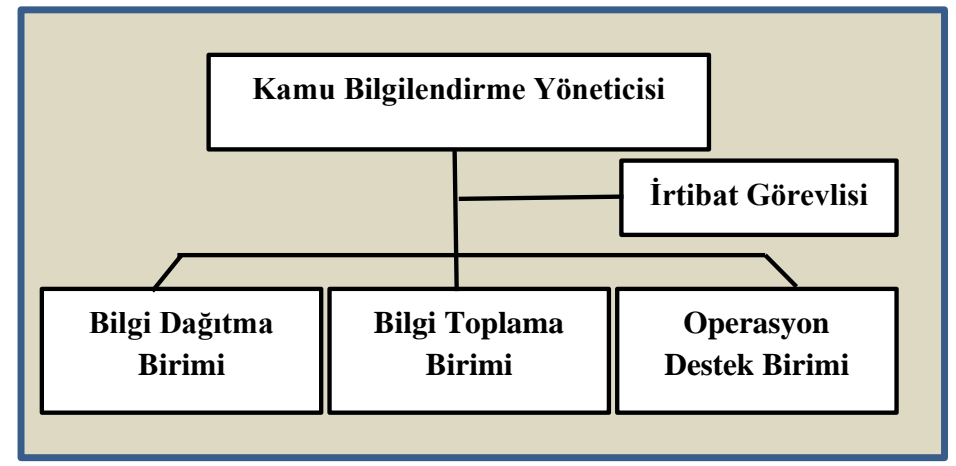

Şekil 1: Ortak Bilgilendirme Merkezi Organizasyon Şeması

\section{Sonuç, Yorum ve Öneriler}

Normal zamanlarda da, herhangi bir afet ve/veya acil durum zammında da iletişim, bir yöneticisinin elindeki en güçlü araçlardan biridir. Her iki durumda da Doğru iletişim olmadan yanlış bilgi ve iletişim bozukluğu gelişebilir ve bunun sonucunda dramatik durumlar yaşanabilir. Stratejik İnsan Kaynakları Yönetimindeki iletişim yaklaşımı ile Afet ve Acil Durum Yönetiminde İletişim yönetiminin benzer özellikler gösteren bir karakteristiği sahip olduğu söylenebilir. Olağan zamanlarda yapılan iletişim faaliyetleri gibi olası afet ve acil durumlarda da, çalışanlar, müşteriler ve diğer paydaşlarla iletişim kurmak kritik bir rol oynar. Etkili iletişim yoluyla çalışanlar sadece ne beklendiğini değil aynı zamanda afet ve/veya acil durum sırasında rolleri hakkında bilgi sahibi olabilirler. Aynı şekilde tüm paydaşların da bilgilendirilmesi ve gerektiğinde yardımlaşmayı sağlayacak planlama çalışmalarının yapılması, kesintisiz ve doğru bilgi akışını temin edecektir. $\mathrm{Bu}$ vasıta ile şeffaf ve güvenilir bir yönetim sergilemek mümkün olabilir.

Hem stratejik insan kaynakları yönetiminde iletişim hem de afet ve acil durum yönetimindeki iletişim temel benzerlikler üzerine kurgulanabilir olsa da, her organizasyonun kendine has olan dinamiklerinden dolayı bu çalışmaların organizasyona özel olarak gerçekleştirilmesi, istenilen hedefe ulaşılması açısından önemli bir noktadır. Kitle iletişimi, kamusal iletişim ve bireyler arası iletişim her iki konuda da önemli yer teşkil etmektedir. Bu üç farklı iletişim şeklinin aynı yöntem ile tasarlanması hem planlama açısından hem de uygulamaya yönelik olarak büyük kolaylık sağlayabilir. Her iletişim yöntemi için kullanılacak iletişim araçları, insan kaynağı ve gerekli malzeme ile ekipman kaynağı önceden belirlenip bir plan dâhilinde oluşturulması halinde, iletişim fonksiyonunun kesintisiz ve doğu bir şekilde gerçekleşmesini temin edebilir. Bu yaklaşımla oluşturtulacak metodolojiyi düzenli egzersiz ve tatbikatlar iler test ederek olası eksiklikler ve zayıflıklar kolaylıkla görülerek hızlı bir biçimde düzeltici faaliyetler ile giderilebilir. 


\section{Kaynakça}

[1] Uyarlıgil C. ve diğerleri. (2008) İnsan Kaynakları Yönetimi, Beta, İstanbul.

[2] Öğüt A. ve diğerleri. (2004) Stratejik İnsan Kaynakları Yönetimi Bağlamında Örgütlerde İşgören Motivasyonu Süreci, Sayı: 12, ss. 277- 290.

[3] Dündar G.İ.(2018) Arel Üniversitesi, Sosyal Bilimler Enstitüsü, İşletme Yönetimi doktora programı, Stratejik İnsan kaynakları Yönetimi

[4] Özgen ve diğerleri. (2002), İnsan Kaynakları Yönetimi, Nobel Kitabevi, Adana

[5] Yılmaz E.G.(2001), İnsan Kaynakları Yönetiminde Etkin İletişimi Gerçekleştirme Koşulları, Marmara İletişim, S.11

[6] Uysal, G. (2003), Rol Farklılaşmasının İletişime Etkisi ve Johari Modeli C.Ü. İktisadi Ve İdari Bilimler Dergisi, 4(1).

[7] Koca, G.Ş. (2016) İletişimde Johari Penceresi: Hastane Yöneticileri, Hekimler Ve Hemşirelerin İletişim Beceri Düzeylerinin Kişisel Acilim Ve Geri Bildirim Düzeyleri Üzerine

[8] Smith, D. (2003). Business continuity and crisis management. Business Continuity Management, 27-33.

[9] Communicating in Times of Crisis: HR's Role [web] 2012,

URL:https://www.yourerc.com/blog/post/communicating-in-times-of-crisis-hrs-role, 22 Temmuz 2020 tarihinde kullanılmıştır.

[10] Varlıer, P. (2016), Strategic approach to HR management during crisis, Procedia - Social and Behavioral Sciences 235.

[11] Five Communication Tips to Help Emergency Managers Succeed [web] 2020, https://safetymanagement.eku.edu/blog/Five-Communication-Tips-to-Help-EmergencyManagers-Succeed, 22 Temmuz 2020 tarihinde kullanılmıştır.

[12] İskender. H. ve Kadığglu. M. (2005), Acil durumlarda basın ve halkla ilişkiler, İTÜ Press [13] Açıklamalı Afet Terimleri Sözlüğü AFAD 2014, Ankara.

[14] The importance of communication in a crisis, [web] 2012, https://easymerlin.com/theimportance-of-communication-in-a-crisis/, 22 Temmuz 2020 tarihinde kullanılmıştır.

[15] Basic Guidance for Public Information Officers ( PIOs). National Emergency Management System ( NIMS). FEMA Publishing. 2007 